\title{
IMPACTO DA GREVE DOS PROFESSORES PARA A EVASÃO DOS ALUNOS DO CURSO DE ADMINISTRAÇÃO NA UFAM
}

\author{
Karoane Leitao da Fonseca* \\ Ruberlene Fonseca de Souza* \\ Geraldo Vieira da Costa***
}

RESUMO: A greve é um direito regido por lei, sendo um instrumento usado pelas organizações sindicais visando melhorias no ambiente de trabalho docente. Nesse sentido o artigo busca identificar o impacto da greve dos professores na evasão dos alunos de Administração na UFAM, segundo a percepção do corpo discente desse curso, utilizando o método quantitativo, questionários com escala Likert e o programa Excel, para geração de tabelas e gráficos. Foram respeitados os requisitos éticos na aplicação dos questionários e na condução da pesquisa. Dentre os resultados alcançados destaca-se que os alunos do curso de Administração sentem-se prejudicados devido à greve dos professores porque esta, segundo eles, afeta o calendário acadêmico, mas que dificilmente trocariam a atual instituição por outra congênere, apesar da greve.

PALAVRAS-CHAVE: Curso de Administração; Educação superior; Evasão escolar; Greve docente.

\section{THE IMPACT OF PROFESSORS`' STRIKE ON ADMINISTRATION STUDENTS' QUITTANCE IN UFAM}

ABSTRACT: Strikes, a right ruled by law, are used by trade unions for the improvement of teachers' work milieu. Current paper identifies the impact of professors' strike on the quittance of students of the Course of Administration in the UFAM, according to the opinion of the studies of the same course. Questionnaires with Likert scale and Excel program were employed for tables and graphs. Ethical requirements were complied with in the application of questionnaires and in the conduction of research. Results show that students of the Course of Administration felt impaired because of the professors' strike, since it jeopardized the school timetable. Howe-

Discente na Faculdade de Estudos Sociais no curso de Administração da Universidade Federal do Amazonas (UFAM), Brasil. E-mail: karoane96@hotmail.com

** Discente na Faculdade de Estudos Sociais no curso de Administração da Universidade Federal do Amazonas (UFAM), Brasil.

*** Doutor em Psicologia pela Universidade de São Paulo (USP). Docente associado da Universidade Federal do Amazonas (UFAM), Brasil. 
ver, they would not transfer themselves to another institution in spite of the strike.

KEY WORDS: Course of Administration; Higher education; Quittance; Teachers's strike.

\section{INTRODUÇÃO}

A greve no Brasil é disciplinada pela Lei 7.783/89, sendo a suspensão coletiva temporária e pacífica, total ou parcial, de prestação pessoal de serviços a empregados. A greve é um ato legal que é exercido por um conjunto de pessoas que gera uma ação positiva ou negativa que, no caso do setor educacional, atinge diretamente os alunos. Uma dessas consequências é a evasão escolar.

Segundo Costa (1991), a evasão escolar é determinada como a saída do estudante do curso de forma definitiva ou temporária, levando em consideração vários motivos, sejam eles financeiros ou até mesmo a desmotivação com o curso. No caso das universidades federais, outro fator que pode contribuir para a ocorrência da evasão é a greve dos professores. Nesse sentido, uma pesquisa longitudinal realizada pela Associação Nacional dos Dirigentes das Instituições Federais de Ensino Superior/Sindicato Nacional/Associação Brasileira dos Reitores das Universidades Estaduais e Municipais/Secretaria de Educação Superior do MEC (ANDIFES/ABRUEM/ SESU/MEC) em 1996, nas universidades federais do Brasil, identificou a evasão dos alunos na ordem de $19,71 \%$ na área de Ciências Sociais Aplicadas.

A presente pesquisa limita-se ao curso de bacharelado em Administração, modalidade presencial, na Universidade Federal do Amazonas (UFAM), localizado no câmpus de Manaus. Esse curso tem mais de 50 anos de existência na universidade, possui os turnos diurno e noturno e é ofertado também na modalidade a distância (EaD).

Brito (2009) descreve o objetivo do curso de Administração na universidade citada de acordo com o prescrito na Lei no 4.769/65, de 09 de setembro de 1965, regulamentada por meio do decreto $\mathrm{n}^{\mathrm{o}} 61.934 / 67$, como sendo o de formar profissionais capacitados a exercerem, nos vários campos organizacionais, as atividades correlatas à área de administração.

Nas instituições de ensino em que ocorrem greves percebe-se a evasão de 
discentes distintas em duas maneiras, conforme Polydoro (2000, apud ASSIS, 2013), que estabelece dois conceitos de evasão: a) evasão do curso - que consiste no abandono do curso sem a sua conclusão; e b) evasão do sistema - que reflete o abandono do aluno do sistema universitário.

A greve, sendo um tema polêmico na UFAM, influencia diversas formas de quem usufrui do ensino e atinge a maior parte de quem está dentro da sala de aula, causando inúmeros problemas, dos quais esta pesquisa pretende elencar alguns deles.

Dessa maneira, a intenção desta pesquisa é investigar, segundo a percepção dos alunos, o impacto exercido pela greve dos professores em relação à evasão de alunos do curso de Administração na UFAM. Subsidiariamente, o estudo orientou-se por:

- Mapear os alunos matriculados no curso de Administração;

- Levantar informação da percepção dos alunos sobre a greve; e

- Avaliar o grau de evasão de alunos no período normal e no período pósgreve.

\section{O CURSO DE ADMINISTRAÇÃO DA UFAM}

A UFAM foi criada em 11 de janeiro de 1909, chamada de Escola Unificada Livre de Manaós, com os cursos de ciências humanas que, vinculados à faculdade de ciências jurídicas e sociais, foram inaugurados no ano seguinte, dia $1^{\circ}$ de março. O Departamento de Administração (DA) teve sua história acoplada à Faculdade de Ciências econômicas, posteriormente denominada Faculdade de Estudos Sociais (FES). No âmbito da FES, em 1966, foi implantado o curso de Administração, conforme a resolução $n^{0} 09 / 65$, de 20 de novembro de 1965. O decreto $n^{0} 61.934$, de dezembro de 1967 , regulamentou e detalhou a Lei $n^{0} 4.769$, estabelecendo o campo e a atividade do Administrador como profissão liberal.

No decorrer do ano de 1965 foram propostos os números de vagas iniciais para os alunos ingressantes no curso de Administração, sendo este quantitativo re- 
gulamentado em 1967. De acordo com UFAM (2017), o aumento de vagas no curso de Administração, diurno e noturno, no decorrer do tempo é apresentado na figura a seguir:

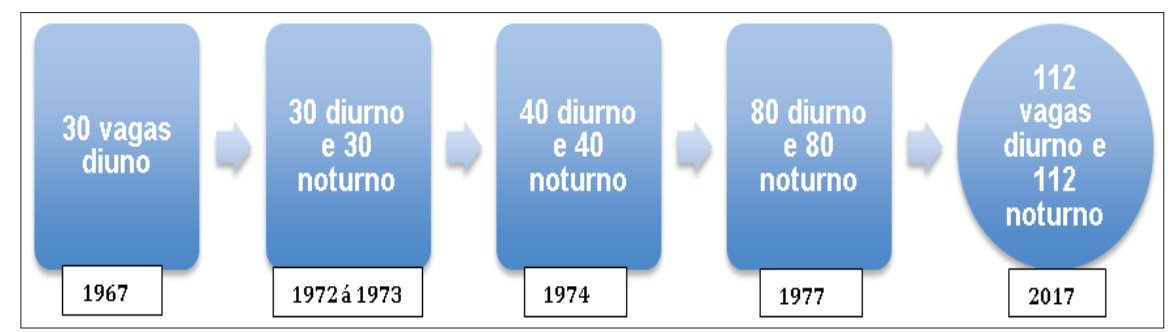

Figura 1. Evolução de vagas do curso de administração na UFAM desde 1966 até 2017 Fonte: Site da UFAM (2017).

\section{GREVE DOS PROFESSORES}

O direito de greve no Brasil é alçado à categoria de direito fundamental, estando a sua previsão no Título II "Dos Direitos e Garantias Fundamentais" da Constituição Federal de 1988. A greve passou por uma fase da proibição com uma dupla qualificação: ilícito civil e ilícito penal antes de ser assegurada pela CF88. A greve, então, passa a ser assegurada como um direito, conforme consta na Constituição Federal de 88 sobre a Lei $n^{0} 7.783 / 1989$

A greve pode ser conceituada como a paralisação de atividade em protesto contra determinada circunstância, ocorrendo em qualquer organização social, inclusive nas que são privadas e públicas. Os servidores públicos podem exercer seu direito constitucional e deflagrar greve utilizando o artigo $9^{\circ}$ da Lei ordinária 7.783/89 que conceitua a greve como a suspensão coletiva temporária e pacífica, total ou parcial, de prestação de serviço a empregados, como se vê:

Art. $9^{\circ}$ É assegurado o direito de greve, competindo aos trabalhadores decidir sobre a oportunidade de exercê-lo e sobre os interesses que devam por meio dele defender.

$\S 1^{\circ}$ A lei definirá os serviços ou atividades essenciais e disporá sobre o atendimento das necessidades inadiáveis da comunidade. $\S 2^{\circ}$ Os abusos cometidos sujeitam os responsáveis às penas da lei. 
A greve no setor público ainda não foi regulamentada sendo uma realidade sociológica cujas consequências se irradiam para o campo jurídico. O direito de greve pelos funcionários públicos é expresso no artigo 37, VII, da Constituição Federal. O exercício do direito de greve é o meio mais relevante para os empregados em face dos empregadores que detêm muitas vezes, além do capital, os instrumentos de trabalho.

A paralisação é um movimento que pressupõe uma manifestação, é um instrumento democrático e legítimo de resistência e de reivindicação trabalhista. A greve tem o intuito de reivindicar algo, no caso dos professores, especificamente da UFAM, geralmente a luta é por melhores salários e distribuição justa do orçamento da União para a educação.

Segundo informa o Sindicato Nacional das Instituições de Ensino Superior (ANDES-SN, 2016):

O governo vem usando seguidamente o discurso da crise financeira internacional como justificativa para cortes de verbas nas áreas sociais e para rejeitar todas as demandas feitas pelos servidores públicos federais por melhores condições de trabalho, remuneração e, consequentemente, qualidade no serviço público. [...].

Contudo, a paralisação possui efeitos que impactam diretamente os alunos durante e após a greve, como a interrupção das aulas com a consequente readequação do calendário acadêmico. O aluno, considerado o elo mais fraco da corrente grevista, é ressaltado por Clilson Júnior (2015) da seguinte maneira:

Greve é o último recurso que qualquer trabalhador tem para pressionar o gestor. Mas as consequências também devem ser levadas a reflexões, primeiro por ser parte mais fraca de todo o processo, o estudante, que sofre com tal decisão.

De acordo com as informações obtidas na Associação de Docentes da UFAM (ADUA, 2017), houve paralisações nos seguintes anos:

- 1980 - paralisações de 26 dias;

- 1981 - paralisação de 21 dias;

- 1982 - paralisações de 32 dias; 
- 1984 - paralisações de 84 dias;

- 1993 - paralisações de 31 dias;

- 1994 - paralisações de 50 dias;

- 1998 - paralisações de 104 dias;

- 2000 - paralisações de 87 dias;

- 2001 - paralisações de 108 dias;

- 2003 - paralisações de 59 dias;

- 2005 - paralisações de 112 dias;

- 2012 - paralisações de 125 dias, considerada a maior greve registrada;

- 2015 - paralisações de 30 dias.

\section{EVASÃO DOS ALUNOS}

Os fatores que contribuem para a evasão do aluno na universidade começam desde o ensino médio, pois se cria uma expectativa em relação ao curso superior almejado e, quando alcançado este objetivo, algumas vezes ocorre a frustração em relação à universidade ou a própria área em que está inserido. Segundo Bueno (1999)

[...] a evasão enquanto parte de uma questão mais ampla da escolha profissional não se contém em poucos aspectos, mas se caracteriza por um conjunto de fatores que são multiplicados e que vão definir as atitudes e motivações do estudante universitário.

Um determinado aluno decide trancar ou desistir do curso matriculado, isso significa uma despesa de tempo e de recurso para ambos (Universidade e aluno), ou seja, perdem todos aqueles que estão envolvidos no processo educacional direto ou indiretamente como professores, a universidade e o governo. Quando um aluno se forma no período correto, a universidade recebe recursos por aluno equivalente como se fossem bonificações, e para as autarquias entende-se que a universidade forma constantemente profissionais (LOBO, 2012). Pode-se dizer que a sociedade perde também com a desistência do aluno, pois é mais um profissional que deixa de entrar no mercado de trabalho. 
Segundo Rosa (2014), a evasão é uma ocorrência no sistema educacional que se manifesta a partir de três nuances:

Existem [...] três modalidades principais de evasão, sendo elas as seguintes: a) evasão do curso: desligamento do curso superior em razão do abandono, o que pode ocorrer por não realização da matrícula, transferência de instituição de ensino, mudança de curso, trancamento ou exclusão por desatendimento a alguma norma institucional; b) evasão da instituição, que se caracteriza pelo desligamento da instituição na qual o aluno está matriculado; c) evasão do sistema, que configura o abandono, definitivo ou temporário, do sistema de educação superior.

Uma pesquisa realizada pelo Ministério da Educação (MEC) em 2013 constatou que a evasão dos alunos das universidades públicas chega a 40\%. Assim como Lobo (2011), o MEC discorre com grande preocupação sobre o impacto dessa desistência dos alunos especialmente no que diz respeito aos cofres públicos.

\section{MÉTODOS DE PESQUISA}

Neste tópico, apresentam-se os métodos utilizados para identificar a percepção dos discentes sobre a greve dos professores e a consequente evasão dos alunos do curso de Administração na UFAM. A pesquisa tem perspectiva quantitativa, descritiva, com as informações representadas estatisticamente. Documentos de apoio foram coletados junto às instâncias da Pró-reitoria de Ensino de Graduação (PROEG) para a obtenção da quantidade de alunos ingressantes e egressos do curso pesquisado e outras informações esclarecedoras no âmbito do estudo.

A unidade de análise foi o curso de graduação em Administração da UFAM, situado na Faculdade de Estudos Sociais, envolvendo os alunos matriculados do $1^{\circ}$ ao $9^{\circ}$ período.

Para o cálculo do tamanho da amostra aleatória simples foram usados os critérios estabelecidos por Barbetta (1994), aplicados à amostra com população finita, com erro amostral de $7 \%$.

Considerando o número de alunos ingressantes (1205) de 2011 até 2017 
que foram afetados com a greve de 2012 e 2015, foram aplicados 174 questionários nas turmas da manhã e noite, sendo 87 questionários para cada turno, atividade que durou em torno de cinco dias do segundo semestre de 2017.

O questionário aplicado continha 20 perguntas cujas afirmativas foram elaboradas de acordo com escala Likert, com graus variando de 1 a 5 .

Para o tratamento e análise dos dados obtidos foi utilizado o programa $M i$ crosoft Office Excel como ferramenta estatística para todos os cálculos, para a obtenção das médias e geração de gráficos de cada questão. Com isso foi interpretada, na sequência, cada uma das questões, tendo sempre em vista os objetivos da pesquisa.

\section{RESULTADOS}

$\mathrm{Na}$ apresentação dos resultados foi considerada, em acordo com a escala de 1 a 5 utilizada, a média das respostas obtidas. A média 1,0 significa que o escore obtido está muito fraco e 5,0 representa a força máxima de presença do escore; 3,0 é o ponto de indiferença.

A partir da distribuição das médias em gráficos, estas foram organizadas de forma a possibilitar uma apreciação da força mínima, máxima e do ponto de indiferença dos escores.

Quadro 1. Resultado do Questionário

(Continua)

\begin{tabular}{|c|c|c|}
\hline Valor & Variável & Média \\
\hline Força mínima & Sinto-me beneficiado devido à greve dos professores. & 1,8 \\
\hline Força mínima & Eu estou preparado para uma nova greve dos professores. & 2,0 \\
\hline Força mínima & Se houvesse uma oportunidade eu trocaria de instituição. & 2,3 \\
\hline Força mínima & Eu apoio a greve dos professores. & 2,4 \\
\hline Força mínima & A greve dos professores me faz pensar em desistir do curso. & 2,5 \\
\hline Força mínima & $\begin{array}{l}\text { Eu acredito que greve é o melhor meio para reivindicar os direitos } \\
\text { dos professores. }\end{array}$ & 2,6 \\
\hline Força mínima & Eu me sinto prejudicado em relação ao horário do curso. & 2,6 \\
\hline
\end{tabular}


(Conclusão)

\begin{tabular}{|c|l|c|}
\hline \multicolumn{1}{|c|}{ Valor } & \multicolumn{1}{|c|}{ Variável } & Média \\
\hline Força mínima & $\begin{array}{l}\text { Sinto-me com dificuldade em alguma matéria devido à má formação } \\
\text { básica. }\end{array}$ & 2,6 \\
\hline Força mínima & Eu apoio a didática dos professores. & 2,9 \\
\hline Indiferença & Eu almejo outro curso. & 3,1 \\
\hline Indiferença & Sinto-me motivado a estar em sala de aula. & 3,3 \\
\hline Indiferença & Sinto-me com dificuldade em alguma matéria. & 3,4 \\
\hline Indiferença & A minha expectativa em relação ao curso está sendo atendida. & 3,4 \\
\hline Indiferença & Eu estou satisfeito com um curso de administração. & 3,5 \\
\hline Indiferença & O curso de administração foi a minha primeira opção. & 3,6 \\
\hline Indiferença & Após a greve percebo um declínio na quantidade de alunos. & 3,8 \\
\hline Indiferença & Eu acredito que a greve influencia para a evasão dos alunos. & 3,9 \\
\hline Força máxima & Sinto-me prejudicado devido à greve dos professores & 4,1 \\
\hline & $\begin{array}{l}\text { Sinto-me prejudicado por conta da readequação do calendário aca- } \\
\text { dêmico. }\end{array}$ & 4,2 \\
\hline Força máxima & 4,3 \\
\hline Força máxima & Eu tenho apoio da minha família para fazer o curso. & \\
\hline
\end{tabular}

Fonte: Elaborado pelas autoras.

Essa apreciação, em síntese, resultou nas seguintes considerações acerca da greve docente:

a) Força mínima das respostas

Rios (2010) diz que "é o menor; o mais pequeno".

Os resultados indicaram que os alunos do curso de Administração da UFAM não se sentem beneficiados com a greve dos professores e não estão preparados para uma nova greve e, dependendo da situação, apesar da greve, percebem que são poucos os alunos que trocariam de instituição caso surgissem oportunidades. Observa-se, no Quadro 1, grande quantidade em respostas de força mínima.

b) Escores situados em torno do ponto de indiferença

De acordo com Lucian (2015), "o questionamento sobre o papel do ponto 
neutro como instrumento de anulação da questão ou realmente uma atitude neutra", sendo assim considera-se que houve uma quantidade de alunos que mostrou-se indiferente quanto às seguintes questões: que a greve é o melhor meio para reivindicar os direitos dos professores; que há dificuldade em alguma disciplina em função da greve; que a expectativa em relação ao curso está sendo atendida; que, independentemente da greve, apoiam a didática dos professores; que se sentem prejudicados em relação ao horário do curso; que se sentem motivados em estar na sala de aula; e que almejam mudar para outro curso.

c) Força máxima das respostas

Conforme Lucian (2015) representa que há uma concordância plena com as questões de acordo com o Quadro 1. Os resultados obtidos indicaram que os alunos do curso de Administração acreditam que a greve docente tem relevante influência na evasão dos alunos do curso, pois até percebem um declínio na quantidade de alunos após a greve. Independentemente de haver ou não greve, os alunos sentem um forte apoio da família para dar continuidade ao curso. Percebem, ainda, que há um relevante prejuízo em sua formação devido à greve dos professores com reflexo, principalmente, por conta da necessidade de readequação do calendário acadêmico.

\section{CONSIDERAÇÕES FINAIS}

Conforme o embasamento teórico apresentado a greve é um direito legal, que na UFAM vem causando impactos, que influencia de certa forma a vida acadêmica dos alunos.

A partir dos resultados dessa pesquisa e, de acordo com os objetivos almejados neste estudo, pode-se adiantar que a greve dos professores da UFAM, conforme percebida pelos alunos do curso de Administração, possui certo impacto negativo na formação e na vida universitária. Do quadro negativo, merece destaque o prejuízo causado pela readequação do calendário acadêmico o que, de certa forma, provoca um alongamento no tempo de duração de seu curso. Entretanto, é relevante o fato de os alunos pesquisados terem revelado que, apesar da greve, dificilmente trocariam a atual instituição por outra congênere, mas que é possível ter evasão.

A atual pesquisa deixa a contribuição para outras possíveis pesquisas poden- 
do aprofundá-la um pouco mais sobre o tema, investigar alunos evadidos da UFAM e de outras Universidades Federais.

\section{REFERÊNCIAS}

ANDIFES, ABRUEM, SESU/MEC. Diplomação, retenção e evasão nos cursos de graduação em instituições de ensino superior públicas. Revista da Avaliação da Educação Superior, v. 1, n. 2, 1996. Disponível em: < http://www.andifes.org.br/ diplomacao-retencao-e-evasao-noscursos-de-graduacao-em-instituicoes-de-ensinosuperior-publicas/> Acesso em: 20 dez. 2016.

BARBETTA, P. Estatística aplicada às Ciências Sociais. Florianópolis: Ed. da UFSC, 1994.

BRASIL. Lei $\mathbf{n}^{\mathbf{0}} \mathbf{7 . 7 8 3}$, de 28 de Junho de 1989. Dispõe sobre o exercício do direito de greve, define as atividades essenciais, regula o atendimento das necessidades inadiáveis da comunidade, e dá outras providências. Disponível em: < http://www. planalto.gov.br/ccivil_03/leis/L7783.htm > . Acesso em: 22 jan. 2017.

BRASIL. Constituição (1988). Lei n ${ }^{0}$ 7783/89. Constituição da República Federativa do Brasil. Brasília, Senado, 1988.

BRITO, R.M. 100 anos de UFAM. Manaus: Ed. da UFA, 2009. p. 391.

BUENO, J.L. O. A evasão de aluno. Jornal da USP, São Paulo, n. 240, p. 2, 08 a 14 fev. 1999.

COSTA, A.L. da. Evasão dos cursos de graduação da UFRGS em 1985, 1986 e 1987. Porto Alegre: UFRGS, 1991.

COSTA, A.L. Disponível em: < http://www.adua.org.br/pagina.php?cod=1>C: 1

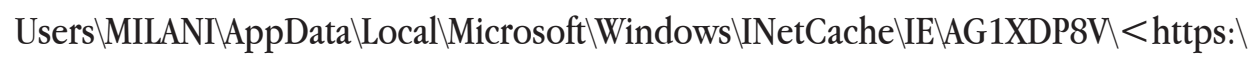
www.adua.org.br \pagina.php?cod=1> Acesso em: 20 dez. 2016. 
COSTA, A.L. Disponível em: < http://www.adusp.org.br/index.php/254-movimentodocente/universidades-federais/greve/1416-nota-do-andes-por-que-osas-professoresas-das-instituicoes-federais-estao-em-greve > . Acesso em: 20 dez. 2016.

CLILSON JÚNIOR. Professores e as consequências da greve. Disponível em: < https://www.clickpb.com.br/colunistas/clilsoncol/professor-e-as-consequencias-da-greve-197824.html>. Acesso em: $20 \mathrm{dez} .2016$.

LOBO, M.B.C.M. Panorama da evasão no ensino superior brasileiro: aspectos gerais das causas e soluções. Instituto Lobo/Lobo \& Associados Consultoria. 2011. Disponível em: < https://www.abmes.org.br/abmes/public/arquivos/documentos/Final_Apostila_Palestra_ABMES_Evas\%C3\%A3o_Modo_de_Compatibilidade.pdf $>$. Acesso em: 15 jan. 2017.

LUCIAN, R. Repensando o uso da escala Likert: tradição ou escolha técnica? Revista Brasileira de Pesquisas de Marketing, Opinião e Mídia, São Paulo, 2006. v. 9, n. 1, p. 12-28, jan.-abr. 2016. Disponível em: < http://www.revistapmkt.com.br/ Portals/9/Revistas/v9n1/2_Repensando\%20o\%20Uso\%20da\%20Escala\%20Likert\%20 Tradi\%C3\%A7\%C3\%A3o\%20ou\%20Escolha\%20T\%C3\%A9cnica\%20-\%20PORTUGU\%C3\%8AS.pdf.>. Acesso em: 08 abr. 2018.

MORAES, A. Anos que ocorreram a greve. Adua, Manaus. 25 set. 2017. Entrevista concedida a Karoane Leitão e Ruberlene de Souza.

POLYDORO, S.A.J. O trancamento de matriculas na trajetória acadêmica do universitário: Concepções de saída e de retorno à instituição. 2000. 175f. Tese (Doutorado em Educação) - Faculdade de Educação, Universidade Estadual de Campinas, Campinas, 2000.

PROEG. Manaus 12 fev. 2017. Disponível em: < http://proeg.ufam.edu.br/cursos-oferecidos/campus-manaus >. Acesso em: 22 jan. 2017.

RIOS, D.R. Grande dicionário unificado da língua portuguesa. São Paulo: DCL, 2010. 
ROCHA, R.I. O direito de greve na legislação brasileira. Âmbito Jurídico, Rio Grande, v. 16, n. 111, abr. 2013. Disponível em: < http://www.ambitojuridico.com.br/ site/?n_link=revista_artigos_leitura\&artigo_id=12748>. Acesso em: 02 jan. 2017.

ROSA, C.M. Limites da democratização da educação superior: entraves na permanência e a evasão na Universidade Federal de Goiás. Poíesis Pedagógica, Catalão (GO), v. 12 , n. 1, p. 240-257, jan./jun. 2014. Disponível em: < https://revistas.ufg.emnuvens.com.br/poiesis/article/download/31219/16813 > . Acesso em: 01 fev. 2017.

UFAM, Faculdade de estudos sociais. Manaus. Disponível em: <http://www.fes. ufam.edu.br/index.php?option $=$ com_content $\&$ view $=$ article $\&$ id $=109 \&$ Itemi$\mathrm{d}=93$ \&lang $=\mathrm{pt}>$. Acesso em: 22 jan. 2017.

Recebido em: 15/03/2018 Aceito em: 16/04/2018 